\title{
PRELIMINARY PLANNING EFFICIENCY EVALUATION FOR SCHOOL BUILDINGS CONSIDERING THE TRADEOFFS OF MOOP AND PLANNING PREFERENCES
}

\author{
Min-Yuan $\mathrm{CHENG}^{\mathrm{a}}$, Ching-Shan $\mathrm{CHEN}^{\mathrm{b}}$ \\ ${ }^{a}$ Department of Construction Engineering, National Taiwan University of Science and Technology, Taiwan, ROC \\ ${ }^{b}$ Department of Architecture, Chaoyang University of Technology, Taiwan, ROC
}

Received 10 Oct 2011; accepted 12 Apr 2012

\begin{abstract}
Seismic resistance and cost effectiveness are often two important building planning objectives for architects. However, these objectives nearly always share a negative correlation with each other, which can cause planning delays and confusion. The conflict between these two is a Multi-Objective Optimization Problem (MOOP). Besides, building planning often encompasses both subjective and objective factors. However, most current efficiency evaluation methods focus on the latter and underemphasize the former. Current efficiency evaluation methods are thus not optimized for actual building planning needs. The aim of this study is to develop a new planning efficiency evaluation approach to resolve the above problems. Research methods include the indifference curve, efficient frontier and Data Envelopment Analysis (DEA). The indifference curve deduced the subjective planning preferences of architects; efficient frontier theory constructed the efficient frontier of school buildings; and DEA evaluated the efficiency of various building factors objectively. A total of 326 school buildings in Taichung City, Taiwan in an empirical study designed to illustrate proposed approach effectiveness. The results show that using only objective evaluation or subjective recognition is insufficient to explain the true nature of building planning. Findings can serve as benchmarks for inefficient school buildings at preliminary planning stage.
\end{abstract}

Keywords: school buildings, indifference curve, efficient frontier, data envelopment analysis, multi-objective optimization problem, benchmark.

Reference to this paper should be made as follows: Cheng, M.-Y.; Chen, C.-S. 2014. Preliminary planning efficiency evaluation for school buildings considering the tradeoffs of MOOP and planning preferences, Journal of Civil Engineering and Management 20(2): 211-222. http://dx.doi.org/10.3846/13923730.2013.801890

\section{Introduction}

Architects typically regard seismic resistance and cost effectiveness as two important objectives of building planning and design work (Cheng, Chen 2011) and they will work to achieve adequate structural safety using the minimum acceptable amount of material (Zekeriya, Yusuf 2010). These two objectives are often in conflict. Seismic-resistant structures are typically not particularly cost effective and buildings designed to conserve costs may provide inadequate seismic resistance. This conflict, a Multi-Objective Optimization Problem (MOOP), poses a significant challenge to building planning and design work; moreover, efficiency evaluation methods discussed in the literature mostly evaluate objective building factors and ignore subjective factors related to architect planning preferences. Building planning and design incorporate both subjective (e.g. architect preferences) and objective factors (e.g. seismic resistance, cost effectiveness), therefore, current efficiency evaluation methods are mostly not suited to evaluate building planning efficiency. This study attempts to develop a new planning efficiency evaluation method, which provides a preliminary solution when considering the tradeoffs of MOOP and planning preferences.

Research methods in this study include the indifference curve, efficient frontier, and Data Envelopment Analysis (DEA). The indifference curve deduces the subjective planning preferences of architects in terms of seismic resistance and cost effectiveness. Efficient frontier theory identifies the case group with the highest seismic resistance among different unit construction costs. The case group with the highest seismic resistance represents the efficient frontier for school buildings and is used as the benchmark for planning buildings of a similar type. The efficiency of various objectives for buildings can be objectively evaluated using the DEA. This article employed the above three theories to develop a new planning efficiency evaluation approach. A total of 326 school buildings in the downtown of Taichung City, Taiwan were investigated as an empirical research to illustrate the methodology. The scope of this research was limited in the downtown of Taichung City since that it is a densely populated area of central Taiwan with over a million people, facing particularly high seismic risk. The main limitations of these school buildings are: (1) the structural materials were RC; (2) the heights of 
the buildings were below five stories; (3) classroom units were oblong, with school buildings in "L", "U", "I" and "T"-shaped configurations; (4) building facades were regular. The detailed characteristics of school buildings in Taichung City will be discussed in Section 3 .

\section{Efficiency evaluation methods of buildings}

A building is generally considered to be an integrated system comprising multiple subsystems (Linzey, Brotchie 1974). Building planning and design is comprehensive and complicated, and integrates subjective and objective factors. Aspects of safety, functionality, beauty, economy and environmental impact are all important planning objectives in building design and execution. Radford and Gero (1980), D'Cruz (1984) developed and demonstrated an application able to resolve complex building design problems, highlighting that efficiency evaluation methods may differ amongst building projects due to assessed objects, time and goals. Building efficiency evaluation methods in common currency today include:

1) Regression analysis: the quantitative study of buildings often employs regression analysis to discuss factors affecting building efficiency. This method often uses a single output variable of a building as the dependent variable and several input variables as the independent variables. Assuming that linear, quadratic or other formulaic functional relationships exist between independent variables and the dependent variable, the least squares method can be used to find the regression equations between independent-dependent variable pairs. Analysis of residual error between the assessed unit and regression equations evaluates efficiency value. This method can employ several input variables to estimate relations between output variables, but output variables cannot be introduced simultaneously into the same model. Chang et al. (2003) adopted the binary regression method to establish a forecast model for predicting earthquake disaster structural hazards. Cho and Awbi (2007) applied multiple regression analysis to study the effect of heat source location in a ventilated room. Hagberg (2010) used linear regression analysis to evaluate field measurements of impact sound in residential buildings.

2) Frontier production approach: this approach borrows the production function of economics to find the production functions of assessed units and measure the production capabilities of assessed units. Using statistical principles, this evaluation method presents advantages including greater objectivity and fewer constraint conditions. However, it must assume production functions, inputs and outputs are quantified in advance and can only be applied to several inputs and a single output. Buck and Young (2007) used a stochastic frontier model to evaluate the potential for energy efficiency gains in the Canadian commercial building sector.

3) Analytic Hierarchy Process (AHP): AHP is an useful tool for multi-objective decision making in its own right. In addition, it has the potential for expediting multiple objective programming analyses (Olson 1988). It is a multicriteria decision making approach in which factors are arranged in a hierarchy structure (Saaty 1990). The most successful applications have come about in group decision making sessions, where the group structures the problem in a hierarchical framework and pairwise comparisons are elicited from the group for each level of the hierarchy. However, the number of pairwise comparison necessary in a real problem often becomes overwhelming (Harker 1987). Wong and Li (2008) used AHP in multicriteria analysis to select intelligent building systems. Lai and Yik (2011) adopted the AHP method to evaluate facility management services for residential buildings in Hong Kong.

4) Multiple Criteria Decision Making (MCDM): MCDM considers optimal decision making for several conflict objectives (or criteria), and can effectively evaluate the efficiency of decision units. Generally, problems can be divided into multi-attribute decision making and multi-objective decision making. It is a suitable method for measuring multiple inputs and outputs. MCDM can handle multiple inputs and outputs simultaneously and approximates actual situations. However, scores and weights of various attributes are difficult to identify in an objective manner. Khajehpour and Grierson (2003) applied multi-criteria optimization concepts for the conceptual design of high-rise office buildings. Hsieh et al. (2004) utilized a fuzzy multi-criteria analysis approach to select planning and design alternatives for public office buildings. Zavadskas et al. (2010) present risk assessment of construction projects based on the MCDM methods. Dejus (2011) analyzed the safety of construction technology projects using MCDM methods at the stages of construction and design.

5) Data Envelopment Analysis (DEA): DEA uses input and output variables to determine the efficient frontier as the basis of measuring decision unit efficiency using a mathematical programming model. This method applies historical data to evaluate the efficiency of decision units to overcome a shortcoming of traditional efficiency evaluation approaches. DEA is currently a diagnostic tool often used by organizations. It can handle multiple input and output variables simultaneously, and the weights do not need to be set in advance. However, DEA only allows improvement in a fixed direction (e.g. input or output direction) and measurement efficiency may be not good enough if input and output data are incorrect. Cheng and $\mathrm{Li}$ (2004) integrated the DEA model and binary integer linear programming models to explore quantitative methods for project location selection. Chung et al. (2006) adopted DEA to benchmark the energy efficiency of commercial buildings. Lee, W. S. and Lee, K. P. (2009) also used DEA to benchmark building energy management performance.

(6) Artificial Intelligence (AI): AI is the study of complex information processing problems that often have their roots in some aspect of biological information processing. Generally, AI consists of the isolation of a particular information processing problem, the formulation of a computational theory for it, the construction of an algorithm that implements it, and a practical demonstration that the algorithm is successful (Marr 1977). There were many practical applications about AI in building 
efficiency evaluation. Plebankiewicz (2009) used fuzzy sets to build a contractor prequalification model. Šešok et al. (2010) adopted simulated annealing method and high performance computing to increase the efficiency of grillage optimization. Chen et al. (2012) integrated two AI techniques, namely, the Support Vector Machine (SVM) and Fast Messy Genetic Algorithm (fmGA) to assess the seismic resistance of school buildings in Taiwan.

Generally speaking, these methods have their own merits and suitabilities, but there exist some shortfalls to the actual building planning and design work: (1) output variables cannot be introduced simultaneously into the same model in regression analysis; (2) the number of pairwise comparison necessary (in AHP) in a real problem often becomes overwhelming; (3) the scores and weights of various attributes are difficult to identify in MCDM; and (4) DEA only allows improvement in a fixed direction. The methods introduced above primarily evaluate objective building factors, but seldom integrate the subjective factors of designers. Thus, they are not compliant with actual building planning and design work, which embraces both subjective and objective factors. The gaps between these methods and actual building planning work are the study trying to fill. The aim of this research is to develop a new planning efficiency evaluation approach in terms of MOOP and planning preferences at preliminary planning stage.

\section{Research methods and theory development}

To resolve conflicts between seismic resistance and cost effectiveness and reflect both subjective and objective factors in the building planning and design, this research developed a methodology that integrates an indifference curve (Mankiw 2008), efficient frontier (Markowitz 1952; Bodie et al. 2009) and DEA (Farrell 1957). The indifference curve is deployed mainly to interpret the subjective planning preference of designers; efficient frontier serves as the basis for architects to benchmark the planning efficiency of inefficient school buildings; and DEA helps evaluate the objective efficiency of buildings. The above three theories were integrated to develop a new planning efficiency evaluation approach that considers the tradeoffs of MOOP and planning preferences. Research methods and theory development in this approach are discussed in the following.

\subsection{Indifference curve}

This study used the seismic performance index $I_{s}$ developed by the National Center for Research on Earthquake Engineering (NCREE) as the basis for designing school building seismic resistance (Hwang et al. 2005; Chung et al. 2005). Unit construction cost of the school building was adopted as the basis for cost effectiveness. As shown in Figure 1, if the unit construction cost is arranged along the X-axis, the seismic performance index $I_{s}$ is arranged along the $\mathrm{Y}$-axis, and assuming the unit construction cost of school building $A$ is $U_{A}$, then the seismic performance index obtained is $I_{A}$. The unit construction cost of school building $B$ is $U_{B}$, and the obtained seismic performance index is $I_{B}$. If the architect's degree of satisfaction is the same as the result, the line (or curve) from point $A$ to point $B$ represents the indifference curve. In the plane consisting of unit construction cost and seismic performance index, different slopes represent the components of different unit construction costs and seismic performance indexes, which show different planning preferences of architects in terms of unit construction costs and seismic performance indexes. In this article, the indifference curve slope is used to interpret the planning preferences of architects and defines five planning preference types (Cheng, Chen 2011). These five types include: (1) equal preference for cost effectiveness and seismic resistance (the indifference curve slope $\mathrm{m}=1$ ); (2) extreme preference for seismic resistance (indifference curve slope $\mathrm{m}=0$ ); (3) extreme preference for cost effectiveness (indifference curve slope $\mathrm{m}=\infty$ ); (4) greater preference for seismic resistance (slope $\mathrm{m}$ is between 0 and 1); and (5) greater preference for cost effectiveness (slope $\mathrm{m}$ is between 1 and $\infty$ ). These five planning preference types can fully interpret architect preferences and contain all possible architect planning preferences in terms of seismic resistance and cost effectiveness.

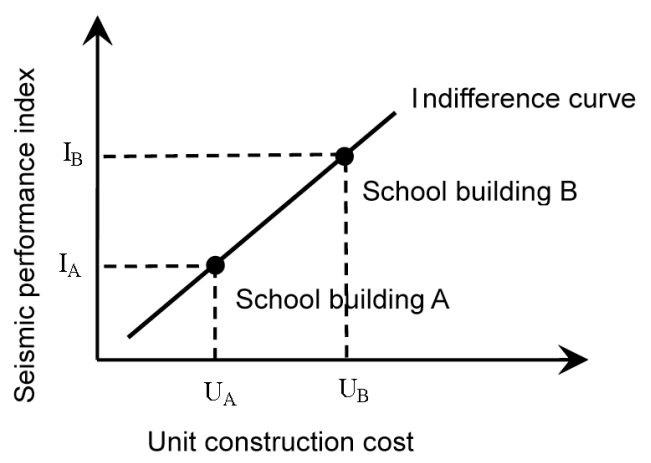

Fig. 1. Indifference curve of school building planning

\subsection{Efficient frontier}

Efficient frontier theory was employed to properly evaluate the planning efficiency of targeted school buildings. In economics, the efficient frontier is the curve of all efficiency investment portfolios. The "efficiency investment portfolio" refers to a type of investment portfolio able to consider expected return as a desirable thing or variance of return as an undesirable thing (Markowitz 1952). This research adopted the concept of efficiency frontier theory to construct the efficient frontier of the school buildings.

As shown in Figure 2, the points represent school buildings planning in terms of seismic resistance and cost effectiveness. Each point represents the planning of one school building. While school buildings D and $\mathrm{G}$ bear the same unit construction cost, school building $\mathrm{D}$ has a higher seismic performance index. Thus, planning for school building D was better than for G. Considering school buildings $B$ and $G$, both have the same seismic performance index, but building $\mathrm{B}$ has a lower unit construction cost. Thus, planning for building $\mathrm{B}$ was better 
than for G. A more efficient curve ABCDEF can be obtained thusly. The points on the curve are more efficient than points on other sets. This curve is the efficient frontier, the points on which provide benchmarks for future school building planning work. The curve can also be used to evaluate the planning efficiency of school buildings not located along the efficient frontier.

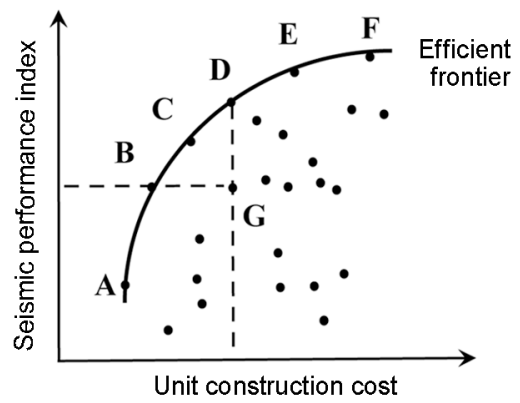

Fig. 2. Efficient frontier of school building planning

Points on efficient frontier ABCDEF can be identified using DEA. If one decision unit has one input variable $(x)$ and one output variable $(y)$, the efficiency of the decision unit can be defined as: $y / x$. If one decision unit $k$ has multiple-input variables $\left(x_{j k}, j=1,2, \ldots m\right)$ and multiple-output variables $\left(y_{r k}, r=1,2, \ldots s\right)$, then input variables and output variables are weighted separately and divided by each other. The relative efficiency can be defined as: $h_{k}=\sum u_{r} y_{r k} / \sum v_{j} x_{j k}$. Thus, relative efficiency can be determined by mathematical programming (MP) as shown in Eqn (1) and Eqn (2). Also known as the CCR model, the mathematical programming equation was developed by Charnes, Cooper and Rhodes (Charnes et al. 1978). The relative efficiency of this model does not even require setting input and output weights in advance.

$$
\begin{array}{ll}
\text { [MP] } \quad \underset{u, v}{\operatorname{Max}} h_{k}=\frac{\sum_{r=1}^{s} u_{r} y_{r k}}{\sum_{j=1}^{m} v_{j} x_{j k}} ; \\
\text { s.t. } \quad \frac{\sum_{r=1}^{s} u_{r} y_{r i}}{\sum_{j=1}^{m} v_{j} x_{j i}} \leq 1, \quad i=1,2,3 \ldots . . n ; \\
& u_{r} \geq 0, \quad r=1,2, \ldots . . s ; \\
& v_{j} \geq 0, \quad j=1,2, \ldots . . m,
\end{array}
$$

where: $h_{k}$ is the input efficiency value of decision unit $k$; $u_{r}$ is the virtual multiplier of the $r$ th output and $v_{j}$ is the virtual multiplier of the $j$ th input.

Eqn (1) was utilized to solve the virtual multiplier of maximum input efficiency of decision unit $k$. Because the input efficiency value must be between 0 and 1, Eqn (2) was used to prevent the virtual multiplier from valuing the input efficiency of any decision unit above 1. The virtual multiplier combination of maximum efficiency value was solved under the same constraint conditions for the input efficiency values of all decision units.

Based on the above principle, this paper regarded each school building as a decision unit. Unit construction cost was set as the input variable and seismic performance index was regarded as the output variable. The relative efficiencies of all school buildings were determined using DEA and the results were used to construct the efficient frontier of the sample space. The efficient frontier curve served as the basis to measure the planning efficiency of inefficient school buildings.

\subsection{Definitions of seismic, economic and planning efficiencies}

In Section 2.2, the curve ABCDEF obtained using DEA was the efficient frontier curve. Points on the curve were more efficient than points on other sets and provided paragon values for planning future school buildings; moreover, the curve can be used to evaluate the planning efficiency of school buildings not on the efficient frontier.

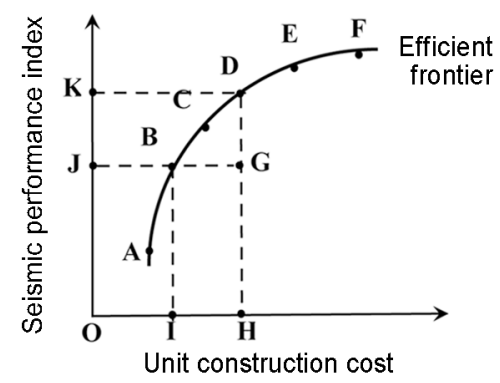

Fig. 3. School building planning efficiency evaluations

As shown in Figure 3, the $\mathrm{X}$-axis represents unit construction cost and the Y-axis represents the seismic performance index. School building B, for example, is located on the efficient frontier and is thus the Pareto efficiency unit. School building $G$ is not on the efficient frontier and is thus not as efficient as school building B. Based on the same seismic performance index, the unit construction cost of the building B was $\overline{B G}$ (or $\overline{I H}$ ) less than building G. If the input efficiency of school building $B$ is 1 , the input efficiency of school building $\mathrm{G}$ can be defined as $\overline{J B} / \overline{J G}$ (or $\overline{O I} / \overline{O H}$ ). School building $\mathrm{G}$ is not the Pareto efficiency unit. It can emulate the school building $\mathrm{B}$ used unit construction cost $\overline{O I}$ to achieve seismic performance in$\operatorname{dex} \overline{O J}$. While school buildings $\mathrm{D}$ and $\mathrm{G}$ had the same unit construction cost, the seismic performance index of school building D was $\overline{G D}$ (or $\overline{J K}$ ) more than the school building $\mathrm{G}$. If the output efficiency of school building $\mathrm{D}$ is 1 , the output efficiency of school building $\mathrm{G}$ can be defined as $\overline{H G} / \overline{H D}$ (or $\overline{O J} / \overline{O K}$ ). From the perspective of output efficiency, school building $G$ is also not the Pareto efficiency unit and can imitate the school building $\mathrm{D}$ that used unit construction cost $\overline{O H}$ to reach seismic performance index $\overline{O K}$. 
Architect planning preference is a subjective perception process that can differ greatly from person to person. Planning preference plays an important role when architects do building planning and design work. Typically, certain building planning objectives (or parameters) are determined according to architect planning preferences. There is little discussion in the literature regarding methods to capture the subjective planning preferences of architects within building assessment models. This study used an indifference curve slope to explain subjective planning preferences and determine the preference weight $\alpha$ for seismic resistance and preference weight $\beta$ for cost effectiveness (Cheng, Chen 2011). Using the school building $\mathrm{G}$ in Figure 3 as an example, the definitions of seismic efficiency $(S E)$, economic efficiency $(E E)$ and planning efficiency $(P E)$ are shown in Eqns (3) to (5).

$$
\begin{gathered}
S E=\frac{\overline{O J}}{\overline{O K}} ; \\
E E=\frac{\overline{O I}}{\overline{O H}} ; \\
P E=\alpha \times S E+\beta \times E E,
\end{gathered}
$$

where: $\alpha$ is the preference weight for seismic resistance and $\beta$ is the preference weight for cost effectiveness.

Eqn (3) can be utilized to evaluate the seismic efficiency of school buildings not on the efficient frontier; Eqn (4) can be adopted to evaluate the economic efficiency; and Eqn (5) can be used to evaluate the planning efficiency of school buildings in terms of seismic resistance and cost effectiveness. Eqns (3) and (4) are objective methods for evaluating building efficiency. Eqn (5) is an efficiency evaluation method that integrates subjective and objective factors and complies with actual building planning and design practices.

In Eqn (3) to Eqn (5), only two planning objectives (seismic resistance and cost effectiveness) were considered to calculate planning efficiency. In fact, the concept can be extended to identify planning efficiency when more than three planning objectives are considered. Extension equations are shown in Eqns (6) and (7).

$$
\begin{gathered}
P E=\sum \omega_{j} \times O B_{j} ; j=1,2,3 \ldots . n ; \\
\sum \omega_{j}=1 ; j=1,2,3 \ldots . n,
\end{gathered}
$$

where $\omega_{j}$ is the preference weight for the $j$ th planning objective and $O B_{j}$ is the efficiency value of the $j$ th planning objective.

\subsection{Benchmarks for different planning preferences}

"Benchmark" refers to a reference point that is identified when measuring relative geographic distance. In management, benchmark is often used to identify an enterprise or organization that is outstanding in its business sector or field. Benchmarking is the systematic process of identifying a measure or evaluation indicator and comparing it to other excellent businesses to identify and define the gap. Learning from the benchmark can help a competitor keep pace and potentially surpass their rival to become the industry leader.

Optimal planning is nearly always influenced by a planner's planning preferences. Thus, if a planned school building is located off the efficient frontier, the architect can identify relevant benchmark and improve planning direction and efficiency based on planning preference and the benchmarking concept. As shown in Figure 4, school buildings $A$ through $E$ are located on the efficient frontier and thus can be used as the benchmarks for other school buildings that are not. It assumes that school building A has the lowest unit construction cost of all buildings on the efficient frontier and school building $\mathrm{E}$ has the highest seismic performance index. School building $\mathrm{C}$ has equal preference (indifference curve slope $\mathrm{m}=1$ ) between the two objectives. As currently planned, school building $\mathrm{F}$ is not on the efficient frontier and five types of planning efficiency improvement directions of $(\mathrm{F} \rightarrow \mathrm{A})$, $(\mathrm{F} \rightarrow \mathrm{B}) \ldots(\mathrm{F} \rightarrow \mathrm{E})$ are proposed based on various architect planning preferences in order to find the benchmarks. The process for doing so is discussed in Section 2.5.

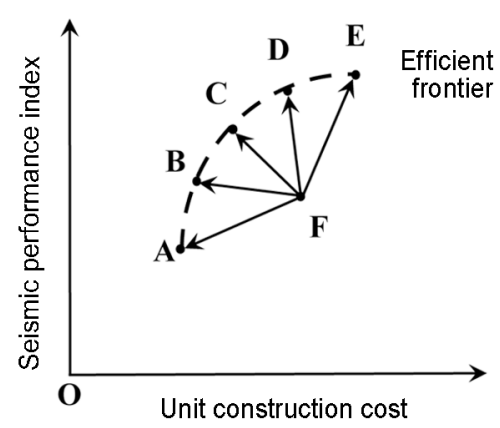

Fig. 4. Benchmarks and planning efficiency improvement

\subsection{Determining benchmarks}

This section discusses use of the indifference curve method to identify the improvement directions of inefficient school buildings and find the benchmarks. Figure 5 presents and illustrative example using point $\mathrm{F}$ in Figure 4.

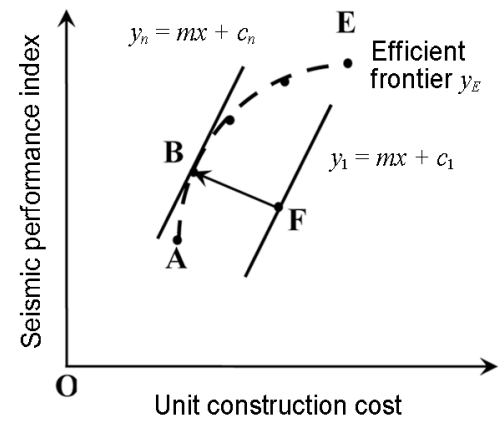

Fig. 5. Benchmark identification method

As shown in Figure 5, if the school building planned by the architect is represented by $\mathrm{F}$, the indifference curve slope $m$ represents architect planning preference. An indifference curve equation $y_{1}=m x+c_{1}$ that passes 
through point $\mathrm{F}$ can thus be identified to represent architect planning attitude. As indifference curve $y_{1}$ is not tangent to efficient frontier curve $y_{E}, \mathrm{~F}$ is inefficient. Equation $y_{k}=m x+c_{k}(k=1,2 \ldots \mathrm{n})$ curves that run parallel to the indifference curve $y_{1}$ can thus be obtained. According to the utility function theory, equations $y_{k}$ represent the same planning preferences of an architect under different utilities. One of the equations $y_{k}$ (e.g. $y_{n}$ ) tangent to equation $y_{E}$ can be found at point $\mathrm{B}$. Therefore, plotting point $\mathrm{B}$ reveals the benchmark that best integrates architect planning preference and the efficient frontier. Table 1 summarizes the benchmark identification methods for five planning preference types.
In Table $1, U_{1}$ and $U_{2}$ represent utility functions of the same architect when planning different school buildings. The utility function was developed by economists to quantify customer satisfaction. If customer preference for commodity combination $a$ is higher than that for commodity combination $b$, utility function $\mathrm{U}$ is used to represent customer preference and $\mathrm{U}(a)>\mathrm{U}(b)$ can be obtained. In accordance with the utility function theory, $U_{1}$ is smaller than $U_{2}$ (Table 1), which represents architect dissatisfaction with school building $\mathrm{F}$ and intends to improve planning efficiencies based on planning preferences in order to attain optimal satisfaction. Table 1 illustrates benchmarks for five planning preference types and

Table 1. Benchmarks for five planning preference types

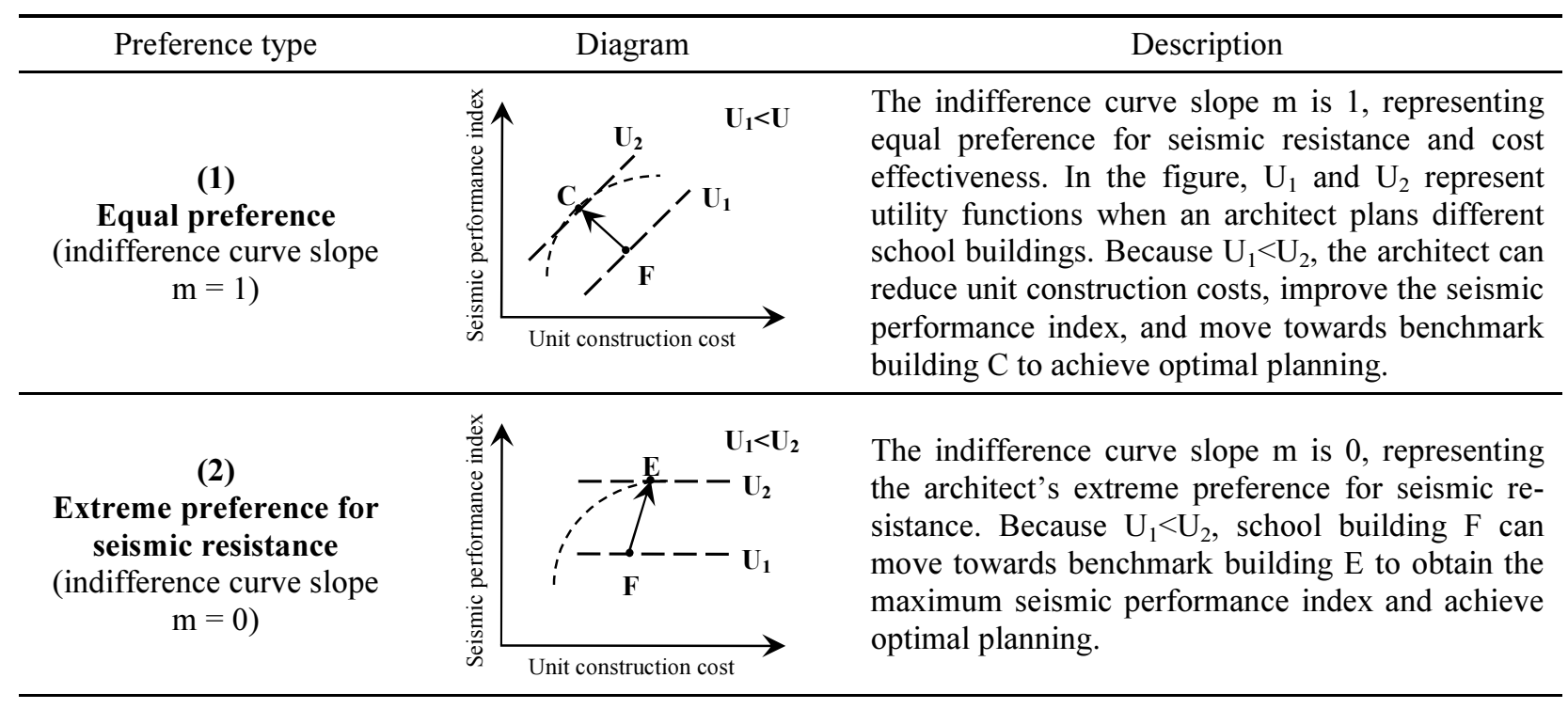

(3)

Extreme preference for cost effectiveness

(indifference curve slope $\mathrm{m}=\infty)$

(4)

Greater preference for seismic resistance (slope $\mathrm{m}$ is between 0 and 1)

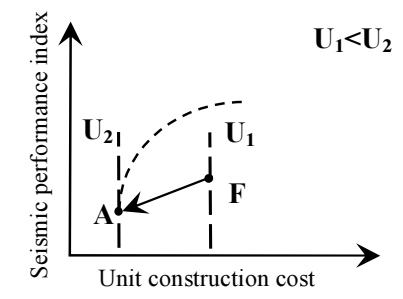

The indifference curve slope $m$ is infinite, representing the architect's extreme preference for cost effectiveness. Because $\mathrm{U}_{1}<\mathrm{U}_{2}$, school building $\mathrm{F}$ can move towards benchmark building A to obtain the minimum unit construction cost and achieve optimal planning.

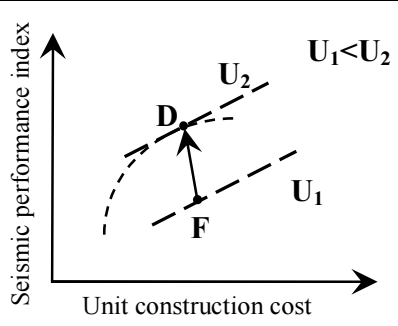

The indifference curve slope $\mathrm{m}$ is between 0 and 1 , representing greater preference for seismic resistance. Because $\mathrm{U}_{1}<\mathrm{U}_{2}$, school building $\mathrm{F}$ can move towards benchmark building $\mathrm{D}$ to improve the seismic performance index and achieve optimal planning.
(5)

Greater preference for cost effectiveness (slope $\mathrm{m}$ is between 1 and $\infty)$

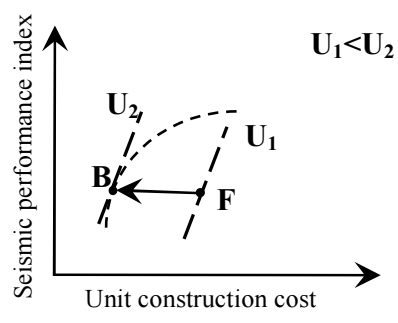

The indifference curve slope $m$ is between 1 and infinity, representing greater preference for cost effectiveness. Because $\mathrm{U}_{1}<\mathrm{U}_{2}$, school building $\mathrm{F}$ can move towards benchmark building B to reduce the unit construction cost and achieve optimal planning. 
planning efficiency improvement directions. The five improvement directions contain all possible architect planning preferences and serve as the basis for architects with different planning preferences to improve planning efficiency. Table 1 integrates DEA with subjective planning preference, which significantly enhances the relevance of this approach to real world situations and improves a disadvantage of DEA that only allows improvement in a fixed direction (e.g. input or output direction).

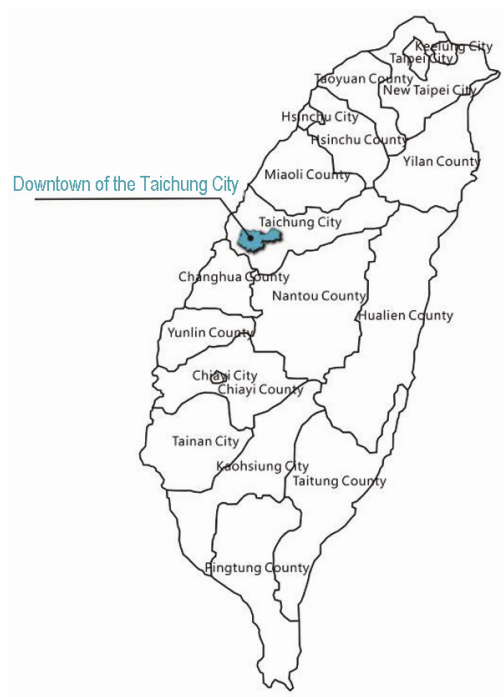

Fig. 6(a). Location of the downtown of Taichung City in Taiwan

\section{Empirical research}

A total of 326 school buildings in the downtown of Taichung City, Taiwan was conducted as an empirical investigation (Chen et al. 2008) to explain and verify methodology developed in Section 2. The location of the downtown of Taichung City in Taiwan was shown in Figure 6(a). Figure 6(b) showed the distribution of schools (each including several school buildings) in the downtown of Taichung City. The architectural characteristics of school buildings are summarized in Table 2 (Cheng, Chen 2011).

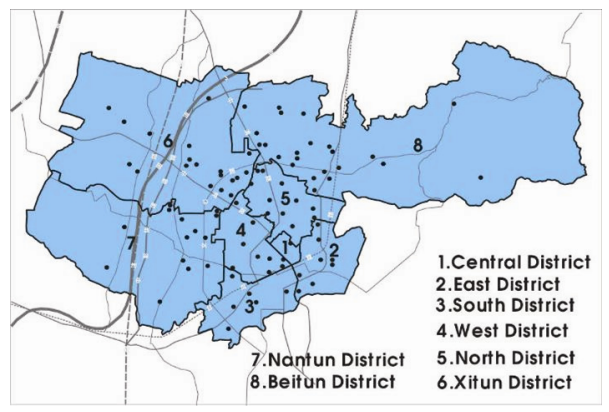

Fig. 6(b). The distribution of schools in the downtown of Taichung City

Table 2. The architectural characteristics of school buildings in Taichung City

\begin{tabular}{cll}
\hline Item & Diagram & Description \\
\hline
\end{tabular}

\begin{tabular}{|c|c|}
\hline $\begin{array}{l}\text { 1. Design of } \\
\text { classroom unit }\end{array}$ & $\begin{array}{l}\text { In this study, building classroom lengths fall into the range of } \\
9.0 \sim 10.0 \mathrm{~m} \text {, widths are approximately } 7.5 \sim 8.0 \mathrm{~m} \text {, areas are approxi- } \\
\text { mately } 75 \mathrm{~m}^{2} \text {, heights are about } 3.5 \mathrm{~m} \text {. }\end{array}$ \\
\hline $\begin{array}{l}\text { 2. Layout of } \\
\text { columns in } \\
\text { classroom unit }\end{array}$ & $\begin{array}{l}\text { The layout of columns in classroom units can be distinguished as } \\
\text { follows: } \\
\text { (1) Two-span column in longitudinal direction and single-span } \\
\text { column in orthogonal; } \\
\text { (2) Three-span column in longitudinal direction and single-span } \\
\text { column in orthogonal; } \\
\text { (3) Two-span column in longitudinal direction and two-span col- } \\
\text { umn in orthogonal; } \\
\text { (4) Three-span column in longitudinal direction and two-span } \\
\text { column in orthogonal. } \\
\text { The classroom unit with two-span column in longitudinal direction } \\
\text { and two-span column in orthogonal is shown in the diagram. }\end{array}$ \\
\hline $\begin{array}{l}\text { 3. Integration of } \\
\text { classroom units }\end{array}$ & $\begin{array}{l}\text { Most classroom units are connected linearly, forming oblong "egg } \\
\text { carton" shaped (passageway in the center and classrooms along both } \\
\text { sides) or "matchbox" shaped (one-sided passageway and continuous } \\
\text { classrooms at another side) buildings. A matchbox shaped building is } \\
\text { shown in the diagram. }\end{array}$ \\
\hline
\end{tabular}


Continued of Table 2

\begin{tabular}{lll}
\hline Item & Diagram & Description \\
\hline
\end{tabular}

4. Layout plan
Classroom units included in this study were in " $\mathrm{L}$ ", "U", "I" or " $\mathrm{T}$ "
shapes, with different building lengths that reflect property character-
istics, student factors and budget.

6. Facade
shape

In sample buildings, facades were basically regular, but some buildings had fewer walls on the ground floor than others. Thus, the entire structure system may have a weak ground floor, which harms overall seismic resistance. The diagram shows a fewer walls on the ground floor.

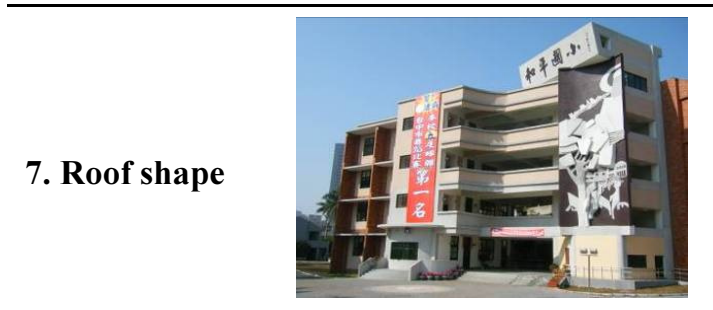

Roof shape and rigidity in RC buildings may affect seismic resistance. Roof shapes of school buildings in this study were flat, inclined, folded or curved. The roofs of older school buildings were mainly flat, and most roofs of the new school buildings were inclined. The flat roof is shown in the diagram.

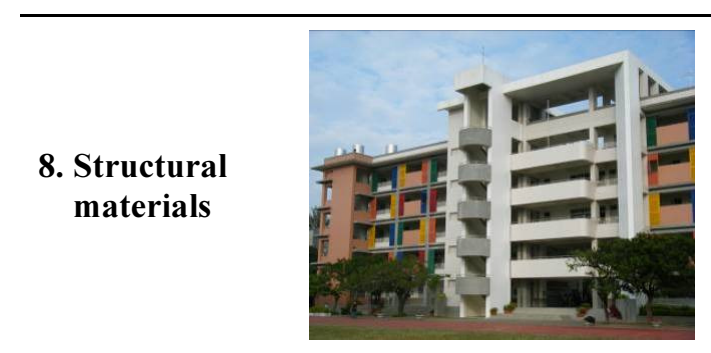

Most school buildings are built with RC. After the 921 Chi-Chi Earthquake in 1999, school buildings of SC and SRC have gradually increased in prevalence. Regardless of whether buildings are built of $\mathrm{RC}, \mathrm{SC}$ or SRC, building heights are less than five stories, so structural materials are proper. RC school buildings are shown in the diagram.

In Table 2, standard classrooms measured 9.0 10.0 m in length and 7.5 8.0 m in width, with an area of about $75 \mathrm{~m}^{2}$. Most classroom units were oblong, with school buildings in "L", "U", "I" and "T"-shaped configurations. Building facades were regular, and the height of most buildings measured below five stories. Roofs of old buildings were mainly flat, while those of new buildings were mostly inclined. The structural materials of most buildings were RC.

For further explaining and verifying methodology developed in Section 2, firstly, the DEA theory was employed to identify an efficient frontier curve for school buildings. The planning efficiency evaluation method developed in this research was then used to evaluate school buildings not on the efficient frontier curve. At last, the findings provided suggestions to improve inefficient school buildings for different planning preferences. Planning efficiency evaluation was divided into: (1) Efficiency evaluation of the same school building under different planning preferences and (2) Efficiency evaluation of different school buildings under the same planning preference.

\subsection{Efficiency evaluation of the same school building under different planning preferences}

The DEA theory was applied to identify the efficient frontier curve in terms of seismic resistance and cost 
effectiveness for the 326 school buildings, as shown in Figure 7. Eqn (8) shows the equation $y_{E}$ for the efficient frontier curve, with each point on the curve more efficient than the points of other sets. The planning efficiency evaluation method proposed in Section 2 can be used for school buildings located off the efficient frontier.

$$
\begin{aligned}
y_{E}= & -0.000000790 x^{4}+0.000454 x^{3}- \\
& 0.0998 x^{2}+9.99 x-258 .
\end{aligned}
$$

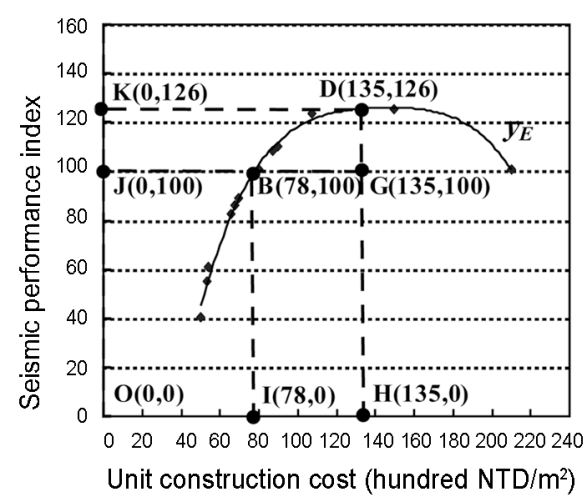

Fig. 7. Building planning efficiency calculation

In Figure 7, school building $\mathrm{G}$ was selected as an illustrative example of a building located off the efficient frontier curve. The unit construction cost of school building G was 135 (hundred $\mathrm{NTD} / \mathrm{m}^{2}$ ) and its seismic performance index was 100 . Using equal preference (indifference curve slope $m=1$ ) as an example, calculation would proceed as follows: As equal preference for seismic resistance and cost effectiveness, so the preference weight $\alpha$ for seismic resistance is 0.5 and preference weight $\beta$ for cost effectiveness is also 0.5 . After calculation, coordinates of points $\mathrm{J}$ and $\mathrm{B}$ are $\mathrm{J}(0,100)$ and $\mathrm{B}(78,100)$ when the seismic performance index is 100 . When the unit construction cost is 135 , coordinates of points $\mathrm{D}$ and $\mathrm{H}$ are $\mathrm{D}(135,126)$ and $\mathrm{H}(135,0)$. In Figure 7 , the coordinate of point I is $\mathrm{I}(78,0)$, and that of point $\mathrm{K}$ is $\mathrm{K}(0,126)$. The calculation process for seismic efficiency $(S E)$, economic efficiency $(E E)$ and planning efficiency $(P E)$ is presented in Eqns (9) through (11).

$$
\begin{aligned}
& S E=\frac{\overline{O J}}{\overline{O K}}=\frac{100}{126}=0.794 ; \\
& E E=\frac{\overline{O I}}{\overline{O H}}=\frac{78}{135}=0.578 ;
\end{aligned}
$$

$$
P E=\alpha \times S E+\beta \times E E=0.5 \times 0.794+0.5 \times 0.578=0.686
$$

The planning efficiency calculation process for one school building with equal preference (indifference curve slope $\mathrm{m}=1)$ was presented above. This research also took the indifference curve slope $\mathrm{m}=0$ (extreme preference for seismic resistance), $\mathrm{m}=0.6$ (greater preference for seismic resistance), $\mathrm{m}=1.6$ (greater preference for cost effectiveness) and $m=\infty$ (extreme preference for cost effectiveness) in order to compare differences be- tween the five planning preference types. Table 3 summarized the calculation processes for $S E, E E$ and $P E$ for the five types.

Table 3. Calculating planning efficiencies for the same school building under different planning preferences

\begin{tabular}{lcccccc}
\hline \multicolumn{1}{c}{$\begin{array}{c}\text { Planning } \\
\text { Preference }\end{array}$} & $m$ & $\alpha$ & $\beta$ & $S E$ & $E E$ & $P E$ \\
\hline $\begin{array}{l}\text { Extreme } \\
\text { preference } \\
\text { for seismic } \\
\text { resistance }\end{array}$ & 0.00 & 1.00 & 0.00 & 0.794 & 0.578 & 0.794 \\
\hline $\begin{array}{l}\text { Greater } \\
\text { preference } \\
\text { for seismic } \\
\text { resistance }\end{array}$ & 0.60 & 0.62 & 0.38 & 0.794 & 0.578 & 0.712 \\
\hline $\begin{array}{l}\text { Equal } \\
\text { preference }\end{array}$ & 1.00 & 0.50 & 0.50 & 0.794 & 0.578 & 0.686 \\
\hline $\begin{array}{l}\text { Greater pref- } \\
\text { erence for cost } \\
\text { effectiveness }\end{array}$ & 1.60 & 0.38 & 0.62 & 0.794 & 0.578 & 0.660 \\
\hline $\begin{array}{l}\text { Extreme pref- } \\
\text { erence for cost } \\
\text { effectiveness }\end{array}$ & $\infty$ & 0.00 & 1.00 & 0.794 & 0.578 & 0.578 \\
\hline
\end{tabular}

Table 3 showed an $S E$ for school building $G$ of 0.794 and $E E$ of 0.578 , under different planning preferences. These values are not affected by planning preferences and objectively reflect school building efficiency. Introducing subjective factors results in significantly different planning efficiency $(P E)$ value that ranges from a maximum value of 0.794 to a minimum value $0.578-\mathrm{a}$ difference of $27.2 \%((0.794-0.578) / 0.794=0.272)$. Such difference reflects the highly disparate viewpoints of different architects toward the same school building. Table 1 can be used as a reference to identify benchmarks necessary to improve school building planning efficiencies under different planning preferences. Table 4 summarized the calculation process and results.

In Table 4, benchmarks are quite different due to different planning preferences. According to the efficient frontier theory and DEA, planning efficiency $(P E)$ of benchmarks all equal 1 and all represent efficient school building planning. Results illustrated the inadequacy of using only objective evaluations and the necessity to consider the subjective planning preferences of architects in building planning and design work.

\subsection{Efficiency evaluation of different school buildings under the same planning preference}

To compare the planning efficiencies of different school buildings given the same planning preference, this research continued to use the equal preference (indifference curve slope $\mathrm{m}=1)$ as an example and selected the three school buildings $\mathrm{L}(123,88), \mathrm{G}(135,100)$ and $\mathrm{M}(147,112)$ for illustration. After calculation, the indifference curve equation $y=x-35$. Figure 8 showed the relationships between the indifference curve of the three school buildings and the efficient frontier $y_{E}$. Calculations followed the same method as above. Table 5 summarized the results. 
Table 4. Benchmarks of the empirical research for five planning preference types

\begin{tabular}{|c|c|c|}
\hline Preference type & Diagram & Description \\
\hline $\begin{array}{l}\text { Extreme preference for } \\
\text { seismic resistance } \\
\text { (indifference curve slope } \\
\mathrm{m}=0 \text { ) }\end{array}$ & 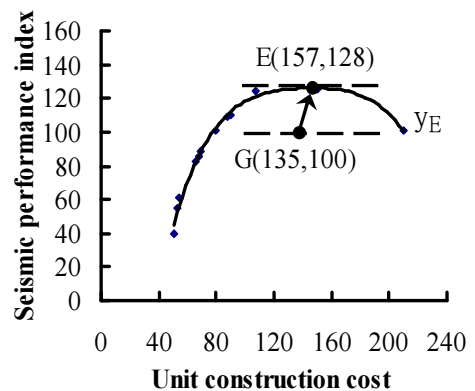 & $\begin{array}{l}\text { (1) Unit construction cost } \\
\left.135 \text { (hundred NTD } / \mathrm{m}^{2}\right) \text { increased to } \\
\left.157 \text { (hundred NTD } / \mathrm{m}^{2}\right) \\
\text { (2) Seismic performance index } \\
100 \text { increased to } 128 \\
\text { (3) Benchmark } \\
\text { School building E }(157,128)\end{array}$ \\
\hline $\begin{array}{l}\text { Greater preference for } \\
\text { seismic resistance } \\
(\text { slope } \mathrm{m}=0.6)\end{array}$ & 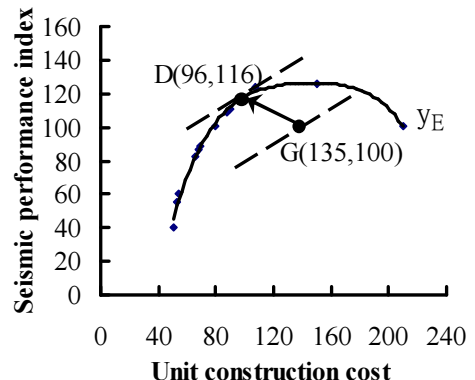 & $\begin{array}{l}\text { (1) Unit construction cost } \\
\left.135 \text { (hundred NTD } / \mathrm{m}^{2}\right) \text { reduced to } \\
\left.96 \text { (hundred NTD } / \mathrm{m}^{2}\right) \\
\text { (2) Seismic performance index } \\
100 \text { increased to } 116 \\
\text { (3) Benchmark } \\
\text { School building D }(96,116)\end{array}$ \\
\hline $\begin{array}{c}\text { Equal preference } \\
\text { (indifference curve slope } \\
\mathrm{m}=1 \text { ) }\end{array}$ & $\begin{array}{l}160 \\
140 \\
0\end{array}$ & $\begin{array}{l}\text { (1) Unit construction cost } \\
135\left(\text { hundred NTD } / \mathrm{m}^{2}\right) \text { reduced to } \\
\left.83 \text { (hundred NTD } / \mathrm{m}^{2}\right) \\
\text { (2) Seismic performance index } \\
100 \text { increased to } 106 \\
\text { (3) Benchmark } \\
\text { School building } \mathrm{C}(83,106)\end{array}$ \\
\hline $\begin{array}{l}\text { Greater preference for } \\
\text { cost effectiveness } \\
(\text { slope } \mathrm{m}=1.6)\end{array}$ & 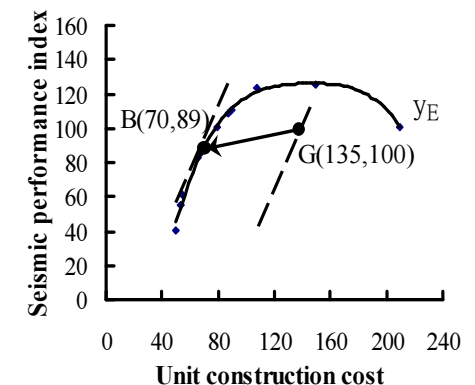 & $\begin{array}{l}\text { (1) Unit construction cost } \\
135\left(\text { hundred NTD } / \mathrm{m}^{2}\right) \text { reduced to } \\
\left.70 \text { (hundred NTD } / \mathrm{m}^{2}\right) \\
\text { (2) Seismic performance index } \\
100 \text { reduced to } 89 \\
\text { (3) Benchmark } \\
\text { School building } \mathrm{B}(70,89)\end{array}$ \\
\hline $\begin{array}{l}\text { Extreme preference for } \\
\text { cost effectiveness } \\
\text { (indifference curve slope } \\
\qquad \mathrm{m}=\infty \text { ) }\end{array}$ & (160) & $\begin{array}{l}\text { (1) Unit construction cost } \\
135\left(\text { hundred NTD } / \mathrm{m}^{2}\right) \text { reduced to } \\
\left.50 \text { (hundred NTD } / \mathrm{m}^{2}\right) \\
\text { (2) Seismic performance index } \\
100 \text { reduced to } 40 \\
\text { (3) Benchmark } \\
\text { School building } \mathrm{A}(50,40)\end{array}$ \\
\hline
\end{tabular}




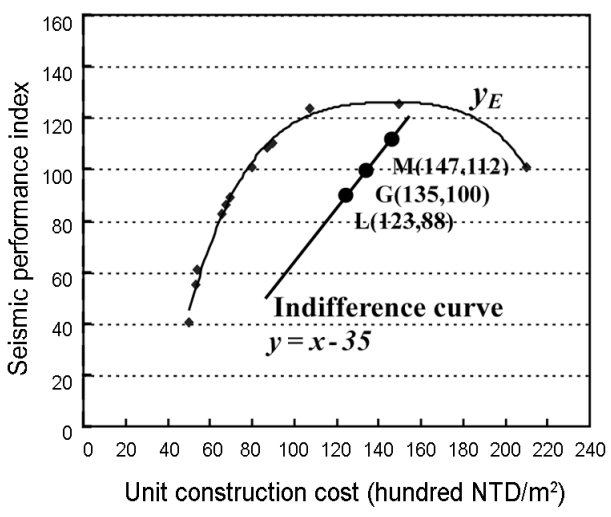

Fig. 8. Calculating planning efficiencies for different school buildings under the same planning preference

Table 5. Calculating planning efficiencies for different school buildings under the same planning preference

\begin{tabular}{|c|c|c|c|c|c|c|c|c|}
\hline$\frac{0}{80}$ & 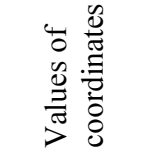 & $O J$ & $O K$ & $\overline{O I}$ & $\mathrm{OH}$ & $S E$ & $E E$ & $P E$ \\
\hline $\mathrm{L}$ & $(123,88)$ & 88 & 125 & 69 & 123 & 0.704 & 0.561 & 0.633 \\
\hline $\mathrm{G}$ & $(135,100)$ & 100 & 126 & 78 & 135 & 0.794 & 0.578 & 0.686 \\
\hline $\bar{M}$ & $(147,112)$ & 112 & 127 & 90 & 147 & 0.882 & 0.612 & 0.747 \\
\hline
\end{tabular}

In Table 5, the results showed that $S E, E E$ and $P E$ of the three school buildings were different, although they were all located on the same indifference curve. In this example, coordinates value correlated positively with building efficiency values. Generally, for school buildings located on the same indifference curve, planning efficiencies were recognized to be the same subjectively due to an equivalent degree of architect satisfaction. However, after calculation, efficiency values differed by $15.3 \%((0.747-0.633) / 0.747=0.153)$. Results showed subjective recognition as not always sufficient and they should be complemented by objective analysis. If school building planning efficiency requires improvement, the indifference curve can move to the upper-left side until the indifference and efficient frontier curves are tangent to each other.

\section{Conclusions}

Seismic resistance and cost effectiveness are two important building planning objectives. However, the natural conflict between the two often leads to architect indecision and delays in building planning and design work. Besides, current efficiency evaluation methods focus on evaluating objective factor efficiencies and seldom address subjective planning preferences of architects. Thus, these methods entail some shortfalls to the actual building planning and design work. This study integrated the indifference curve, efficient frontier and DEA theories to develop a new planning efficiency evaluation method designed to address these shortcomings. To illustrate the proposed approach effectiveness, a total of 326 school buildings in Taichung City, Taiwan were conducted as an empirical survey. The findings can serve as benchmarks for architects to optimize their building planning and design works.

The same approach can be adapted to tens of thousands of school buildings in other cities in Taiwan. Since the empirical survey in Taichung City is quite representative of Taiwanese school buildings, it may have a significant impact upon architects for planning their optimal school buildings.

The results obtained suggest that using only objective evaluation or subjective recognition is insufficient to explain the nature of building planning and design. Therefore, the findings can assist architects to: (a) adopt indifference curve theory to decide their planning preferences to reflect the subjective recognition; (b) construct the efficiency frontiers of buildings via DEA to convey the objective evaluation; and (c) combine the previously discussed theories to find the benchmarks. Thus, in addition to conducting an efficiency analysis of objective factors, the subjective planning preferences of architects could also be considered in order to reflect the true nature of building planning and design.

Homogeneity among school buildings in terms of architectural characteristics makes DEA theory an appropriate approach to constructing their efficiency frontier. This empirical research focused only on school buildings in order to illustrate the proposed methodology. The methodology can be replicated for residential, office and other building types to establish their distinct planning efficiency evaluation approaches. Owing to the limitations of DEA, buildings addressed by the method must be homogeneous operating units. In addition, the number of buildings should be sufficiently large to construct the efficient frontier. These issues should be explored further in future studies.

\section{References}

Bodie, Z.; Kane, A.; Marcus, A. J. 2009. Essentials of investments. $8^{\text {th }}$ ed. Boston: McGraw-Hill. $724 \mathrm{p}$.

Buck, J.; Young, D. 2007. The potential for energy efficiency gains in the Canadian commercial building sector: a stochastic frontier study, Energy 32(9): 1769-1780. http://dx.doi.org/10.1016/j.energy.2006.11.008

Chang, Y. S.; Tu, C. H.; Chao, C. M. 2003. Establishing the forecast model of the hazard of the building in the earthquake disaster by binary regression method-case study at the urban planning region of Chung-Hsing new village, City and Planning 30(3): 223-239 (in Chinese).

Charnes, A.; Cooper, W. W.; Rhodes, E. 1978. Measuring the efficiency of decision making units, European Journal of Operational Research 2(6): 429-444. http://dx.doi.org/10.1016/0377-2217(78)90138-8

Chen, C. S.; Chen, H. A.; Guo, C. Y. 2008. Seismic model of elementary and junior high school buildings in Taichung City by Neural Network and Principal Component Analysis. National Science Council Project No.: NSC 96-2221E-324-050.

Chen, C. S.; Cheng, M. Y.; Wu, Y. W. 2012. Seismic assessment of school buildings in Taiwan using the evolutionary support vector machine inference system, Expert Systems with Applications 39(4): 4102-4110. http://dx.doi.org/10.1016/j.eswa.2011.09.078 
Cheng, E. W. L.; Li, H. 2004. Exploring quantitative methods for project location selection, Building and Environment 39(12): 1467-1476. http://dx.doi.org/10.1016/j.buildenv.2004.03.015

Cheng, M. Y.; Chen, C. S. 2011. Optimal planning model for school buildings considering the tradeoff of seismic resistance and cost effectiveness: a Taiwan case study, Structural and Multidisciplinary Optimization 43(6): 863-879. http://dx.doi.org/10.1007/s00158-010-0553-3

Cho, Y.; Awbi, H. B. 2007. A study of the effect of heat source location in a ventilated room using multiple regression analysis, Building and Environment 42(5): 2072-2082. http://dx.doi.org/10.1016/j.buildenv.2006.03.008

Chung, L. L.; Chien, W. Y.; Yeh, Y. K.; Hwang, S. J.; Hsu, T. Y.; Chiou, T. C., et al. 2005. Simple seismic survey for typical building structures of primary and secondary schools. National Center for Research on Earthquake Engineering, Project No.: NCREE-05-007.

Chung, W.; Hui, Y. V.; Miu, L. Y. 2006. Benchmarking the energy efficiency of commercial buildings, Applied Energy 83(1): 1-14.

http://dx.doi.org/10.1016/j.apenergy.2004.11.003

D'Cruz, N. 1984. Multi-criteria performance model for building design: PhD Thesis. Sydney, University of Sydney.

Dejus, T. 2011. Safety of technological projects using multicriteria decision making methods, Journal of Civil Engineering and Management 17(2): 177-183. http://dx.doi.org/10.3846/13923730.2011.576809

Farrell, M. J. 1957. The measurement of productive efficiency, Journal of the Royal Statistical Society, Series A, General 120(3): 253-281. http://dx.doi.org/10.2307/2343100

Hagberg, K. G. 2010. Evaluating field measurements of impact sound, Building Acoustics 17(2): 105-128. http://dx.doi.org/10.1260/1351-010X.17.2.105

Harker, P. T. 1987. Incomplete pairwise comparisons in the analytic hierarchy process, Mathematical Modelling 9(11): 837-848. http://dx.doi.org/10.1016/0270-0255(87)90503-3

Hsieh, T. Y.; Lu, S. T.; Tzeng, G. H. 2004. Fuzzy MCDM approach for planning and design tenders selection in public office buildings, International Journal of Project Management 22(7): 573-584.

http://dx.doi.org/10.1016/j.ijproman.2004.01.002

Hwang, S. J.; Chung, L. L.; Chien, W. Y.; Yeh, Y. K.; Hsu, T. Y.; Chiou, T. C., et al. 2005. Implementation planning for seismic evaluation and retrofit of elementary school buildings. National Center for Research on Earthquake Engineering, Project No.: NCREE-05-008.

Khajehpour, S.; Grierson, D. E. 2003. Profitability versus safety of high-rise office building, Structural and Multidisciplinary Optimization 25(4): 279-293.

http://dx.doi.org/10.1007/s00158-003-0297-4
Lai, J. H. K.; Yik, F. W. H. 2011. An analytical method to evaluate facility management services for residential buildings, Building and Environment 46: 165-175. http://dx.doi.org/10.1016/j.buildenv.2010.07.012

Lee, W. S.; Lee, K. P. 2009. Benchmarking the performance of building energy management using data envelopment analysis, Applied Thermal Engineering 29(16): 32693273.

http://dx.doi.org/10.1016/j.applthermaleng.2008.02.034

Linzey, M. P. T.; Brotchie, J. F. 1974. Planning and design at the overall building level, Building Science 9(1): 17-28. http://dx.doi.org/10.1016/0007-3628(74)90036-X

Mankiw, N. G. 2008. Principles of Economics. $5^{\text {th }}$ ed. SouthWestern College Pub. 904 p.

Markowitz, H. M. 1952. Portfolio selection, Journal of Finance 7(1): 77-91. http://dx.doi.org/10.2307/2975974

Marr, D. 1977. Artificial intelligence - a personal view, Artificial Intelligence 9(1): 37-48. http://dx.doi.org/10.1016/0004-3702(77)90013-3

Olson, D. L. 1988. Opportunities and limitations of AHP in multiobjective programming, Mathematical and Computer Modelling 11: 206-209. http://dx.doi.org/10.1016/0895-7177(88)90481-5

Plebankiewicz, E. 2009. Contractor prequalification model using fuzzy sets, Journal of Civil Engineering and Management 15(4): 377-385. http://dx.doi.org/10.3846/1392-3730.2009.15.377-385

Radford, A. D.; Gero, J. S. 1980. On optimization in computer aided architectural design, Building and Environment 15: 73-80. http://dx.doi.org/10.1016/0360-1323(80)90011-6

Saaty, T. L. 1990. How to make a decision: the analytic hierarchy process, European Journal of Operational Research 48(1): 9-26. http://dx.doi.org/10.1016/0377-2217(90)90057-I

Šešok, D.; Mockus, J.; Belevičius, R.; Kačeniauskas, A. 2010. Global optimization of grillages using simulated annealing and high performance computing, Journal of Civil Engineering and Management 16(1): 95-101. http://dx.doi.org/10.3846/jcem.2010.09

Wong, J. K. W.; Li, H. 2008. Application of the analytic hierarchy process (AHP) in multi-criteria analysis of the selection of intelligent building systems, Building and Environment 43(1): 108-125. http://dx.doi.org/10.1016/j.buildenv.2006.11.019

Zavadskas, E. K.; Turskis, Z.; Tamošaitiene, J. 2010. Risk assessment of construction projects, Journal of Civil Engineering and Management 16(1): 33-46. http://dx.doi.org/10.3846/jcem.2010.03

Zekeriya, A.; Yusuf, A. 2010. Optimum topology and shape design of prestressed concrete bridge girders using a genetic algorithm, Structural and Multidisciplinary Optimization 41(1): 151-162. http://dx.doi.org/10.1007/s00158-009-0404-2

Min-Yuan CHENG. PhD, Distinguished Professor of Construction Engineering Department in College of Engineering at National Taiwan University of Science and Technology. He is a former Director of Ecological and Hazard Mitigation Engineering Research Centre. His areas of academic research interests include geographic information system, construction automation, management information system, applications of artificial intelligence, construction management process reengineering.

Ching-Shan CHEN. PhD, Associate Professor of the Department of Architecture in College of Design at Chaoyang University of Technology, Taiwan. He is also an architect and a member of Architectural Institute of Taiwan. His areas of academic research interests include applications of artificial intelligence, evolutionary algorithms, multi-objective optimization problem, seismic building, building efficiency evaluation. 